\title{
Potassium Intercalation into Graphite to Realize High-Voltage/Power Potassium-Ion Batteries and Potassium-Ion Capacitors
}

\author{
Shinichi Komaba, ${ }^{1,2 *}$ Tatsuya Hasegawa, ${ }^{1}$ Mouad Dahbi, ${ }^{1,2}$ and Kei Kubota ${ }^{1,2}$ \\ ${ }^{1}$ Department of Applied Chemistry, Tokyo University of Science, Shinjuku, Tokyo \\ 162-8601, Japan \\ ${ }^{2}$ Elements Strategy Initiative for Catalysts and Batteries, Kyoto University, Kyoto \\ 615-8245, Japan
}

*Correspondence: komaba@rs.kagu.tus.ac.jp

\begin{abstract}
Highly reversible potassium intercalation into graphite in carbonate ester solution at room temperature is achieved byelectrochemical reductionat the potential approaching to $\mathrm{K}^{+} / \mathrm{K}$ standard potential which islower than that of $\mathrm{Li}^{+} / \mathrm{Li}$. The intercalation results in formation of stage- $1 \mathrm{KC}_{8}$ compound with delivering $244 \mathrm{mAh} \mathrm{g}^{-1}$ of reversible capacity. The initial irreversible capacity is suppressed by polycarboxylate bindercompared to poly(vinyledene fluoride) binder.The lower potential, good cyclabilty, andexcellent rate capabilityare first demonstrated forenergy storage applications. Because of the lowest potential andweakest solvation among $\mathrm{Li}^{+}, \mathrm{Na}^{+}$, $\mathrm{K}^{+}, \mathrm{Mg}^{2+}$, and $\mathrm{Ca}^{2+}$ ion carriers, potassium shuttlecock mechanism between two insertion materials as "potassium-ion battery" is advantageous for higher-voltage/-power rechargeable batteries. The excellent rate performance is beneficial for the application to hybrid-type capacitor, "potassium-ion capacitor,"as an alternative to lithium-ion capacitors.
\end{abstract}


Keywords:potassium; intercalation;graphite; binder; potassium-ion battery: potassium-ion capacitor

\section{Introduction}

Lithium isbroadly believed to be the best alkali metal element for highenergy density batteriesin terms ofthe lightestatomic weight and lowest standard potential among alkali metals. Lithium-ion batteries have been sophisticated ascommercial rechargeable batteriesfor portable devices and transportation applications since 1991. In spite of the significant progress in lithium-ion technology, its available reserve is unevenly distributed especially in South America, most of countries should therefore depend on the import of lithium resource. Because of unlimited availability of sodium which is the second lightest alkali, sodium-ion batteries made from earth-abundantelements without toxic elementsattractsignificant attention to realize affordable rechargeable batteries which can store highenergy density comparable to lithium-ion batteries. ${ }^{1}$

In Table 1,lithium, sodium, and potassiumare compared as ionic carriersfor non-aqueousrechargeable batteries. Because their ionic size plays a critical role in crystallization of insertion materials, especially for positive electrode, we are experiencing wider variety of Na-ion materials than Li-ion ones, due to significantdifferenceof ionic size between sodium and lithium. ${ }^{2}$ Furthermore, the atomic weight ratios of sodium and potassium against lithium are $3.3(=23 / 6.9)$ and $5.7(=$ 39/6.9), respectively, which convinces us of no chance of sodium- and potassium-based 
batteries.However, this comparison is fairly misleading to understand battery weight becausepurealkali metals are never acceptable for consumer usedue to safety issues. Actually, we should compare formula weight of positive electrode materialsto consider their gravimetric capacity. For instance, the formula weight ratio of(P2-type $\left.\mathrm{Na}_{2 / 3} \mathrm{CoO}_{2}\right) / \mathrm{LiCoO}_{2}$ is only 1.08 , meaning only $8 \%$ weight gain of positive active material in entire Na-ion system. In case of potassium, the ratio of (P2-type $\left.\mathrm{K}_{2 / 3} \mathrm{CoO}_{2}\right) /\left(\mathrm{LiCoO}_{2}\right)$ is 1.19 , in spite of 5.7 times heavier potassium atom. This means that atomic weight of alkali does not remarkably affecttotal weight of batteries.

We note that battery's voltage is very important to realize high-energy density, since energy density (Wh) is determined by multiplying capacity (Ah) by average discharge voltage. A state-of-the-art lithium-ion battery is charged up to $4.4 \mathrm{~V}$ vs. Li, which is limited by anodic decomposition of electrolyte solution resulting in gas evolution.From the same reason, the charge cut-off voltage must belimited to ca. $4.1 \mathrm{~V}$ vs. Na, inevitably resulting in lower energy density than Li-ion. However, the standard potential of potassium is low in voltage ca. $0.1 \mathrm{~V}$ than that of lithium in propylene carbonate (PC) as seen in Table $1 .{ }^{3}$ As reported by Aurbach and coworkers, ${ }^{4}$ the surface film formed in potassium salt PC solution is more stable than that of sodium.A few potassium insertion materials for positive electrode werereported, e.g. Prussian blue thin film, ${ }^{5} \mathrm{FeSO}_{4} \mathrm{~F}^{6}$ and amorphous $\mathrm{FePO}_{4}{ }^{7}$ Potassium can be intercalated into graphite to form $\mathrm{KC}_{8}$ with a stage-1 structure by liquid-phase chemical reaction at ambient temperatures. ${ }^{8}$ These facts motivated us to realize graphite negative electrode for 4 volt class K-ion battery (KIB) and K-ion capacitor (KIC) as we succeeded in 3 volt Na-ion batteries based on Li-ion experiences. In this study, we investigate the electrochemical 
potassium intercalation into graphite and demonstrate attractive redox performance for negative electrodes of non-aqueous potassium-ion batteries and capacitors.

\section{Experimental}

Natural graphite (particle size $3 \mu \mathrm{m}$ ) was mixed with binder, sodium polyacrylate $(\mathrm{PANa})$, sodium carboxymethylcellurose $(\mathrm{CMCNa})$, or poly(vinylydene fluoride) (PVDF) binders in weight ratio of 90:10 in adequate solvent of deionized water or $N$-methylpyrrolidinone. Details of graphite and binders are described in our

previous paper. ${ }^{9}$ The resulting slurrywas uniformly pasted onto aluminium foil or copper foil by doctor blade method, and then carefully dried at $150{ }^{\circ} \mathrm{C}$ for $12 \mathrm{~h}$ in a vacuum prior to cell assembly. The loading on the foils was ca. $0.8-1.0 \mathrm{mg} \mathrm{cm}^{-2}$. Galvanostatic charge-discharge test(between 0.0 and $2.0 \mathrm{~V}$ vs. Kat $-/+25 \mathrm{~mA} \mathrm{~g}^{-1}$ ) and cyclic voltammetry were conducted in a coin-typeK cell and three-compartment beaker-type cell, ${ }^{10}$ respectively.All the cellswere assembled in Ar-filled glove boxwith satisfactorylower dew point below $-80{ }^{\circ} \mathrm{C}$. We handle potassium metal with special care through all experimental works.

Electrolyte solutionused in this study was $1.0 \mathrm{~mol} \mathrm{dm}{ }^{-3} \mathrm{KN}\left(\mathrm{SO}_{2} \mathrm{~F}\right)_{2}$ (potassium bis(fluorosulfonyl)imide, KFSI)or $0.5 \mathrm{~mol} \mathrm{dm}^{-3} \mathrm{KPF}_{6}$ dissolved in ethylene carbonate (EC):diethyl carbonate(DEC) in a 1:1 (v/v) mixture. KFSI (Kanto Chemical), potassium metal, $\mathrm{KPF}_{6}$ (Sigma-Aldrich), LiFSI (Kishida Chemical), NaFSI (Mitsubishi Materials), EC, DEC, PC, and Li- and Na-ion electrolyte solutions (battery grade, Kishida Chemical) were used as received without air exposure. Ex situ X-ray diffraction 
(XRD) was conducted for tested electrodes washed with EC:DEC and then DEC.

\section{Results and discussion}

In order to examine potassium plating, cyclic voltammetry is conducted for nickel mesh as working electrodes because of no $\mathrm{Ni}-\mathrm{K}$ alloying at room temperature. In Figure 1, potassium plating/stripping located at $-0.15 \mathrm{~V}$ vs. $\mathrm{Li}^{+} / \mathrm{Li}$ was observed in $0.5 \mathrm{~mol} \mathrm{dm}^{-3} \mathrm{KPF}_{6} \mathrm{EC}: \mathrm{DEC}$. The reason why $0.5 \mathrm{~mol} \mathrm{dm}^{-3} \mathrm{KPF}_{6} \mathrm{EC}: \mathrm{DEC}$ was used is the facts that $1 \mathrm{~mol} \mathrm{dm}^{-3} \mathrm{KPF}_{6}$ was not completely dissolved into $\mathrm{EC}: \mathrm{DEC}$, resulting in white-coloured dispersion, which may be similar to the condition of low purity $\mathrm{NaPF}_{6}{ }^{11}$, and in addition $\mathrm{KClO}_{4}$ and $\mathrm{KBF}_{4}$ were hardly soluble in EC:DEC and PC in our preliminary test. From Nernst equation, the standard potential of $\mathrm{K}^{+} / \mathrm{K}$ is calculated to be $-0.12 \mathrm{~V}$ vs. $\mathrm{Li}^{+} / \mathrm{Li}$, which agrees with the previous dataof $-0.09 \mathrm{~V}$ calculated for PC shown in Table $1{ }^{3}$ Clearly,reversible potassium deposition was observed without any electrolyte additives, such as fluoroethylene carbonateand vinylene carbonate, ${ }^{12}$ which isprobably due to passivation of potassium metalcompleted by electrolyte decomposition ${ }^{13}$ with low contamination level. ${ }^{14}$ The cyclic voltammogram reveals that potassium plating/stripping occurs at lower potential, which is highly advantageous for higher-energy density design.

The incomplete dissolution of $\mathrm{KPF}_{6}$ powder results in the white dispersion, in addition, $\mathrm{KClO}_{4}$ and $\mathrm{KBF}_{4}$ are almost insoluble in $\mathrm{PC}$. Consequently, we selected and used the only transparent and colorless liquid of $1 \mathrm{~mol} \mathrm{dm}^{-3} \mathrm{KFSI}$, which can be completely dissolved into EC:DEC, in our tests. Figure 1 compares the redox 
properties of graphite electrodes in three different alkali cells. Sodium polyacrylate is selected as the binder toimprovethe solid electrolyte interphase (SEI)-passivation. ${ }^{15}$ In Li cells, the graphite delivers high reversible capacity ofca. $369 \mathrm{mAh} \mathrm{g}^{-1}$ with high initial efficiency to formLiC 6 showing $372 \mathrm{mAh} \mathrm{g}^{-1} \cdot{ }^{10}$ The graphite showed no sodiation activity in the $\mathrm{NaPF}_{6} / \mathrm{EC}: \mathrm{DEC}$ solution as known generally. ${ }^{14 a}, 16$ In case of potassium, the high capacity of $244 \mathrm{mAh} \mathrm{g}^{-1}$ in $0-0.3$ Vis demonstrated, which corresponds to $87 \%$

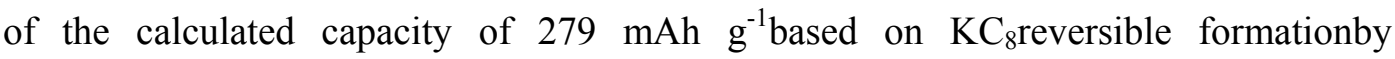
electrochemical reaction.Figure 1 furtherconfirms the same electrochemical propertywhen we used $\mathrm{Al}$ and $\mathrm{Cu}$ current collectors in $\mathrm{K}$ cells, which is consistent of no intermetallic phase of $\mathrm{Cu}-\mathrm{K}^{17}$ and $\mathrm{Al}-\mathrm{K}^{18}$ at room temperature. Adopting $\mathrm{Al}$ foil will be beneficial to practical KIB and KIC as a consequence of its lowercost and lighter weight than $\mathrm{Cu}$ which is necessary for lithium-ion counterparts.

Ex-situ XRD was conducted to identify the reversible redox reaction without air exposure for avoidingoxidative decomposition of $\mathrm{KC}_{8} \cdot{ }^{19}$ Figure 2 reveals phase transition from graphite to stage-one intercalation compound, $\mathrm{KC}_{8}$ (ICSD \#70020), of which the interlayer distance is ca. $5.3 \AA,{ }^{20}$ by the electrochemical reduction. Because it returns to graphite after electrooxidation, potassium ions are reversibly deintercalated in the topotactic manner. From the diffraction lines of graphite and $\mathrm{KC}_{8}$, the interlayer distance increasesupon potassium intercalation from 3.36 and $5.2 \AA$, indicating 1.5 times increase in the distance, which is much significant than that of $\mathrm{LiC}_{6}$ due to the larger ionic size than that of lithium.As stepwise potential variation appears for the $\mathrm{K} /$ graphite cell in Figure 1, phase transition including formation of different stage compounds,such as $\mathrm{KC}_{24}$, is under investigation. 
Figure 3 compares cycle performance of graphite with different binders. The reversible capacity, reversibility, and redox potential of the intercalation are basically identical for PVDF, PANa and CMCNa, except reversibility at the first cycle. Namely the irreversibility is due to SEI formation like lithium and sodium cases, ${ }^{14 a}$ and the initial efficiency is improved by PANa and CMCNa compared to PVDF, as indicated in the figure. This improvement should be attributed to the pre-formed SEI effect of PANa ${ }^{21}$ and $\mathrm{CMCNa},{ }^{21}$ and in addition, to the suppressed defluorination of PVDF. ${ }^{21}$ Though the interlayer distance is expanded $50 \%$ uponelectrochemical potassium intercalation, the volume expansion results in no capacity degradation during $>50$ cycles for PANa, which is likely due to its surface coatability and higher mechanical strength of composite electrodes. ${ }^{9 \mathrm{c}}$ Surface analyses of the graphite electrodeare in progress and will be reported elsewhere.

To further examine discharge rate-capability as KIB or KIC, the PANa electrode wascharged (potassiated) at a low current of $\mathrm{C} / 10$ and then discharged (depotassiated) at different rates as shown in Figure 3d. Surprisingly, capacity loss is hardly observedat $15 \mathrm{C}$ rate despite the polarization of approximately $0.6 \mathrm{~V}$. Note that the polarization includes $0.5 \mathrm{~V}$ potassium stripping polarization at the counter Kelectrode in coin-type cell,which was estimated in three-electrode configuration test at the same condition. Therefore, the actual polarization of graphite electrode is mostly only $0.1 \mathrm{~V}$, which is quite small compared with typical lithium and sodium insertion/de-insertion at carbonaceous electrodes. This is consistent with a recent paper describingthat alkali diffusivity ishigher for $\mathrm{KC}_{8}$ than those forlithiated and 
sodiated graphites at room temperature. ${ }^{22}$ Additionally, as $\mathrm{Al}$ anodic corrosion does not occur in high purity LiFSI EC:EMC electrolyte but is induced by $\mathrm{LiCl}$ impurity in low purity LiFSI, ${ }^{23}$ KFSI electrolyte is expected to have no damage for Al used for positive electrode.

Generally, $\mathrm{K}^{+}$ions have much weaker Lewis acidity among the alkalis, which is important for ion transfer inelectrolyte and at electrode/electrolyte interface. ${ }^{24}$ This causes smaller Stoke's radius of solvated ions, which should lead to larger transport number and higher mobility for $\mathrm{K}^{+}$. Indeed, our measurement reveals that ionic conductivity at ambient temperature is found to be $9.3,9.7$ and $10.7 \mathrm{mS} \mathrm{cm}^{-1}$ for $1 \mathrm{~mol}$ $\mathrm{dm}^{-3}$ LiFSI, NaFSI, and KFSI EC:DEC, respectively, indicating the highest conductivity of $\mathrm{K}$ system. This superior character of $\mathrm{K}^{+}$ions is well known as $\mathrm{KOH}$ aqueous solution practically used in alkaline batteries. Safety issue must be taken into account because potassium metal is violently reactive compared to $\mathrm{Li}$ and $\mathrm{Na}$ metals. It is noticed that its melting point, $64^{\circ} \mathrm{C}$, is much lower than others listed in Table 1 . If dendrite deposition by overcharging KIBs induces the internal short-circuit inside KIB, the dendrite is heated by Joule heat, and then the heat will swiftlyfuse thedendrite which avoids the thermal runaway of KIB.

By realizing graphite negative electrode for KIB and KIC, novel fieldof materials science of potassium insertion materials, binders, salts, organic solvents, additives, solid electrolyte etc. will attract us tonext generation battery and hybrid-capacitor beyond Li-ion and $\mathrm{Na}$-ion. 


\section{Conclusions}

This study demonstrates the graphite-polyacrylate electrode for higher-voltage and -power KIB/KIC operable at room temperature. Although potassium atom is heavier than lithium and sodium ones, promising battery performance is highly expected by future study.

\section{Acknowledgements}

The authors acknowledge Mr. S. Muratsubaki for helpful assistance of ionic conductivity measurement. This study was partly granted by MEXT program "ESICB," and the JST through ALCA program.

\section{References}

1. Yabuuchi, N.; Kubota, K.; Dahbi, M.; Komaba, S., Research Development on Sodium-Ion Batteries. Chemical reviews 2014,114 (23), 11636-11682.

2. Delmas, C.; Braconnier, J.; Maazaz, A.; Hagenmuller, P., Soft Chemistry in AxMO2 Sheet Oxides. Revue de Chimie minerale 1982,19 (4-5), 343-351.

3. Marcus, Y., Thermodynamic functions of transfer of single ions from water to nonaqueous and mixed solvents: Part 3-Standard potentials of selected electrodes. Pure and applied chemistry 1985,57 (8), 1129-1132.

4. Moshkovich, M.; Gofer, Y.; Aurbach, D., Investigation of the electrochemical windows of aprotic alkali metal (Li, Na, K) salt solutions. Journal of The Electrochemical Society 2001,148 (4), E155-E167.

5. Eftekhari, A., Potassium secondary cell based on Prussian blue cathode. Journal of Power Sources 2004,126 (1-2), 221-228. 
6. Recham, N.; Rousse, G.; Sougrati, M. T.; Chotard, J.-N.; Frayret, C.; Mariyappan, S.; Melot, B. C.; Jumas, J.-C.; Tarascon, J.-M., Preparation and Characterization of a Stable FeSO4F-Based Framework for Alkali Ion Insertion Electrodes. Chemistry of Materials 2012,24 (22), 4363-4370.

7. Mathew, V.; Kim, S.; Kang, J.; Gim, J.; Song, J.; Baboo, J. P.; Park, W.; Ahn, D.; Han, J.; Gu, L., Amorphous iron phosphate: potential host for various charge carrier ions. NPG Asia Mater 2014,6, e138.

8. Mizutani, Y.; Abe, T.; Ikeda, K.; Ihara, E.; Asano, M.; Harada, T.; Inaba, M.; Ogumi, Z., Graphite intercalation compounds prepared in solutions of alkali metals in 2-methyltetrahydrofuran and 2,5-dimethyltetrahydrofuran. Carbon 1997,35 (1), 61-65.

9. (a) Komaba, S.; Yabuuchi, N.; Ozeki, T.; Okushi, K.; Yui, H.; Konno, K.; Katayama, Y.; Miura, T., Functional binders for reversible lithium intercalation into graphite in propylene carbonate and ionic liquid media. Journal of Power Sources 2010,195 (18), 6069-6074;(b) Komaba, S.; Yabuuchi, N.; Ozeki, T.; Han, Z.-J.; Shimomura, K.; Yui, H.; Katayama, Y.; Miura, T., Comparative Study of Sodium Polyacrylate and Poly(vinylidene fluoride) as Binders for High Capacity Si-Graphite Composite Negative Electrodes in Li-Ion Batteries. The Journal of Physical Chemistry C 2012,116 (1), 1380-1389;(c) Yabuuchi, N.; Shimomura, K.; Shimbe, Y.; Ozeki, T.; Son, J. Y.; Oji, H.; Katayama, Y.; Miura, T.; Komaba, S., Graphite - Silicon - Polyacrylate Negative Electrodes in Ionic Liquid Electrolyte for Safer Rechargeable Li - Ion Batteries. Advanced Energy Materials 2011,1 (5), 759-765.

10. Komaba, S.; Kumagai, N.; Kataoka, Y., Influence of manganese(II), cobalt(II), and nickel(II) additives in electrolyte on performance of graphite anode for lithium-ion batteries. Electrochimica Acta 2002,47 (8), 1229-1239.

11. Bhide, A.; Hofmann, J.; Katharina Durr, A.; Janek, J.; Adelhelm, P., Electrochemical stability of non-aqueous electrolytes for sodium-ion batteries and their compatibility with Na0.7CoO2. Physical Chemistry Chemical Physics 2014,16 (5), 1987-1998.

12. Komaba, S.; Ishikawa, T.; Yabuuchi, N.; Murata, W.; Ito, A.; Ohsawa, Y., Fluorinated Ethylene 
Carbonate as Electrolyte Additive for Rechargeable Na Batteries. ACS Applied Materials \& Interfaces 2011,3 (11), 4165-4168.

13. Peled, E., The electrochemical behavior of alkali and alkaline earth metals in nonaqueous battery systems - the solid electrolyte interphase model. Journal of The Electrochemical Society 1979,126 (12), 2047-2051.

14. (a) Komaba, S.; Murata, W.; Ishikawa, T.; Yabuuchi, N.; Ozeki, T.; Nakayama, T.; Ogata, A.; Gotoh, K.; Fujiwara, K., Electrochemical $\mathrm{Na}$ insertion and solid electrolyte interphase for hard - carbon electrodes and application to $\mathrm{Na}$ - Ion batteries. Advanced Functional Materials 2011,21 (20), 3859-3867;(b) Kubota, K.; Komaba, S., Practical issues and future perspective for Na-ion batteries. Journal of The Electrochemical Society 2015, in press.

15. Komaba, S.; Okushi, K.; Ozeki, T.; Yui, H.; Katayama, Y.; Miura, T.; Saito, T.; Groult, H., Polyacrylate Modifier for Graphite Anode of Lithium-Ion Batteries. Electrochemical and Solid-State Letters 2009,12 (5), A107-A110.

16. Ge, P.; Fouletier, M., Electrochemical intercalation of sodium in graphite. Solid State Ionics $1988,28,1172-1175$.

17. Pelton, A. D., The $\mathrm{Cu}-\mathrm{K}$ (Copper-Potassium) system. Bulletin of Alloy Phase Diagrams 1986,7 (3), 231-231.

18. Du, Y.; Yuan, X.; Sun, W.; Hu, B., Thermodynamic modeling of the Al-K system. Journal of Mining and Metallurgy, Section B: Metallurgy 2009,45 (1), 89-93.

19. Akuzawa, N.; Fujisawa, T.; Amemiya, T.; Takahashi, Y., Stability of potassium-graphite intercalation compounds in an oxygen atmosphere. Synthetic Metals 1983,7 (1-2), 57-63.

20. (a) Dresselhaus, M. S.; Dresselhaus, G., Intercalation compounds of graphite. Advances in Physics 2002,51 (1), 1-186;(b) Lagrange, P.; Guérard, D.; Hérold, A., Sur La Structure du compose KC8. Annales de Chimie (Paris, France) 1978,3, 143-159. 
21. Dahbi, M.; Yabuuchi, N.; Kubota, K.; Tokiwa, K.; Komaba, S., Negative electrodes for Na-ion batteries. Physical Chemistry Chemical Physics 2014,16 (29), 15007-15028.

22. Wang, Z.; Ratvik, A. P.; Grande, T.; Selbach, S. M., Diffusion of alkali metals in the first stage graphite intercalation compounds by vdW-DFT calculations. RSC Advances 2015,5 (21), 15985-15992.

23. Han, H.-B.; Zhou, S.-S.; Zhang, D.-J.; Feng, S.-W.; Li, L.-F.; Liu, K.; Feng, W.-F.; Nie, J.; Li, H.; Huang, X.-J.; Armand, M.; Zhou, Z.-B., Lithium bis(fluorosulfonyl)imide (LiFSI) as conducting salt for nonaqueous liquid electrolytes for lithium-ion batteries: Physicochemical and electrochemical properties. Journal of Power Sources 2011,196 (7), 3623-3632.

24. Sagane, F.; Abe, T.; Iriyama, Y.; Ogumi, Z., Li+ and Na+ transfer through interfaces between inorganic solid electrolytes and polymer or liquid electrolytes. Journal of Power Sources 2005,146 (1-2), $749-752$. 
Figure 1. (upper) Cyclic voltammograms of $\mathrm{Ni}$ mesh electrode in $0.5 \mathrm{~mol} \mathrm{dm}^{-3} \mathrm{KPF}_{6}$ EC:DEC at $0.05 \mathrm{mV} \mathrm{s}^{-1}$ in beaker-type cell equipped with $\mathrm{Li}^{+} / \mathrm{Li}$ reference electrode. (bottom) Charge-discharge curves of graphite electrode with polyacrylate binder in (a) 1 mol dm ${ }^{-3} \mathrm{LiPF}_{6}$ EC:DMC of Li cell, (b) $\mathrm{NaPF}_{6}$ EC:DEC of Na cell, and (c,d) 1 mol $\mathrm{dm}^{-3}$ KFSI EC:DEC of K cell. Graphite composite electrode was formed on $(\mathrm{a}, \mathrm{c}) \mathrm{Cu}$ and (b,d) Al foils.

Figure 2. EX-situ XRD patterns of graphite-PANa electrode: (a) as prepared, (b) after first reduction at $0.0 \mathrm{~V}$, and (c) after oxidation $2.0 \mathrm{~V}$ in $\mathrm{K}$ cells.

Figure 3. Charge-discharge curves of graphite electrode formed on Al foil with (a) PVDF, (b) PANa, and (c) CMC binders in $1 \mathrm{~mol} \mathrm{dm}^{-3}$ KFSI EC:DEC of $\mathrm{K}$ cells, and (d) oxidation-rate capability for the PANa electrode. 

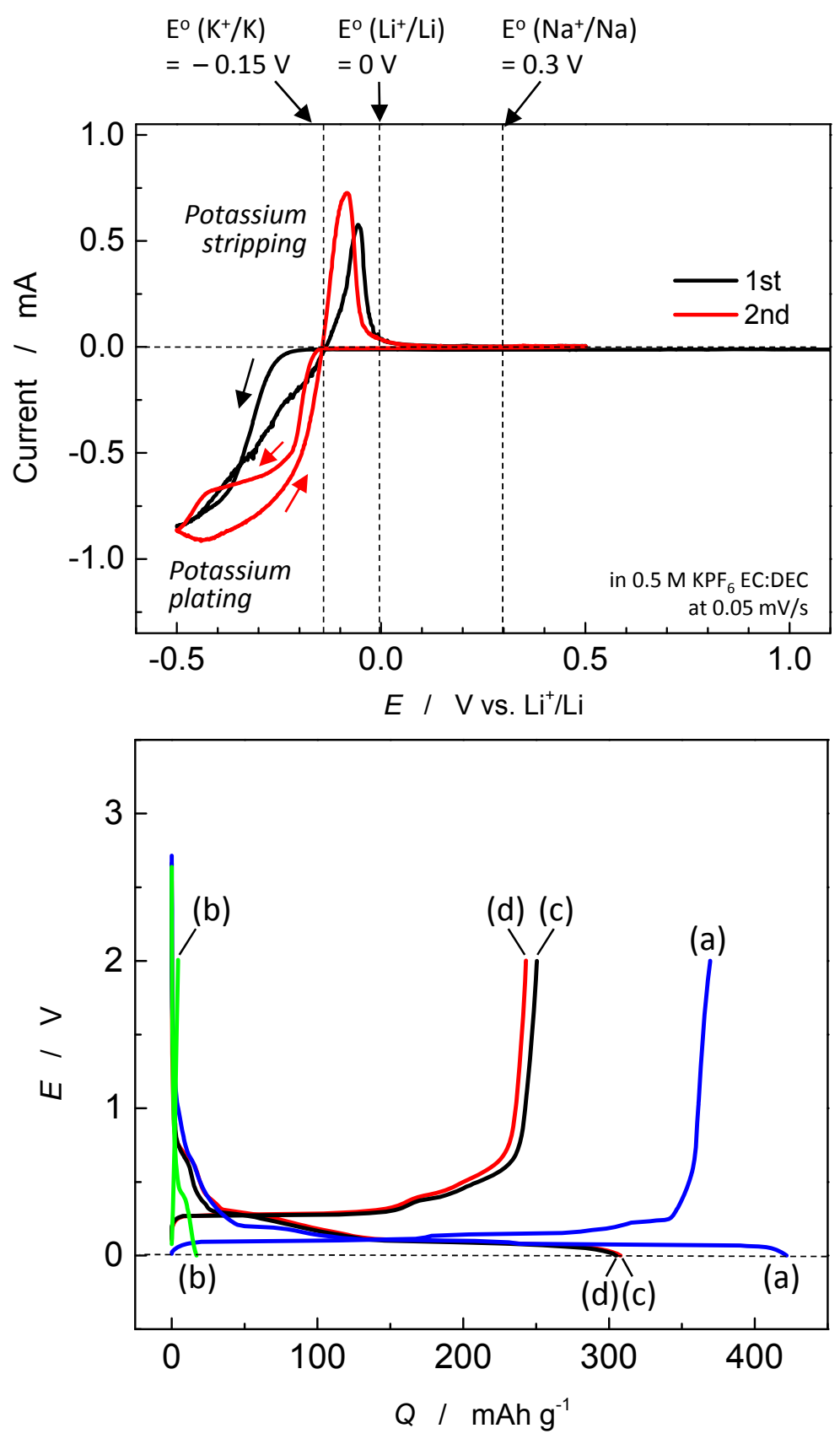

Figure 1. (upper) Cyclic voltammograms of $\mathrm{Ni}$ mesh electrode in $0.5 \mathrm{~mol} \mathrm{dm}^{-3} \mathrm{KPF}_{6} \mathrm{EC}: \mathrm{DEC}$ at $0.05 \mathrm{mV} \mathrm{s}^{-1}$ in beaker-type cell equipped with $\mathrm{Li}^{+} / \mathrm{Li}$ reference electrode. (bottom) Charge-discharge curves of graphite electrode with polyacrylate binder in (a) $1 \mathrm{~mol} \mathrm{dm}^{-3} \mathrm{LiPF}_{6} E C: D M C$ of Li cell, (b) $\mathrm{NaPF}_{6}$ EC:DEC of $\mathrm{Na}$ cell, and (c,d) $1 \mathrm{~mol} \mathrm{dm}^{-3}$ KFSI EC:DEC of K cell. Graphite composite electrode was formed on $(a, c) C u$ and $(b, d)$ Al foils. 


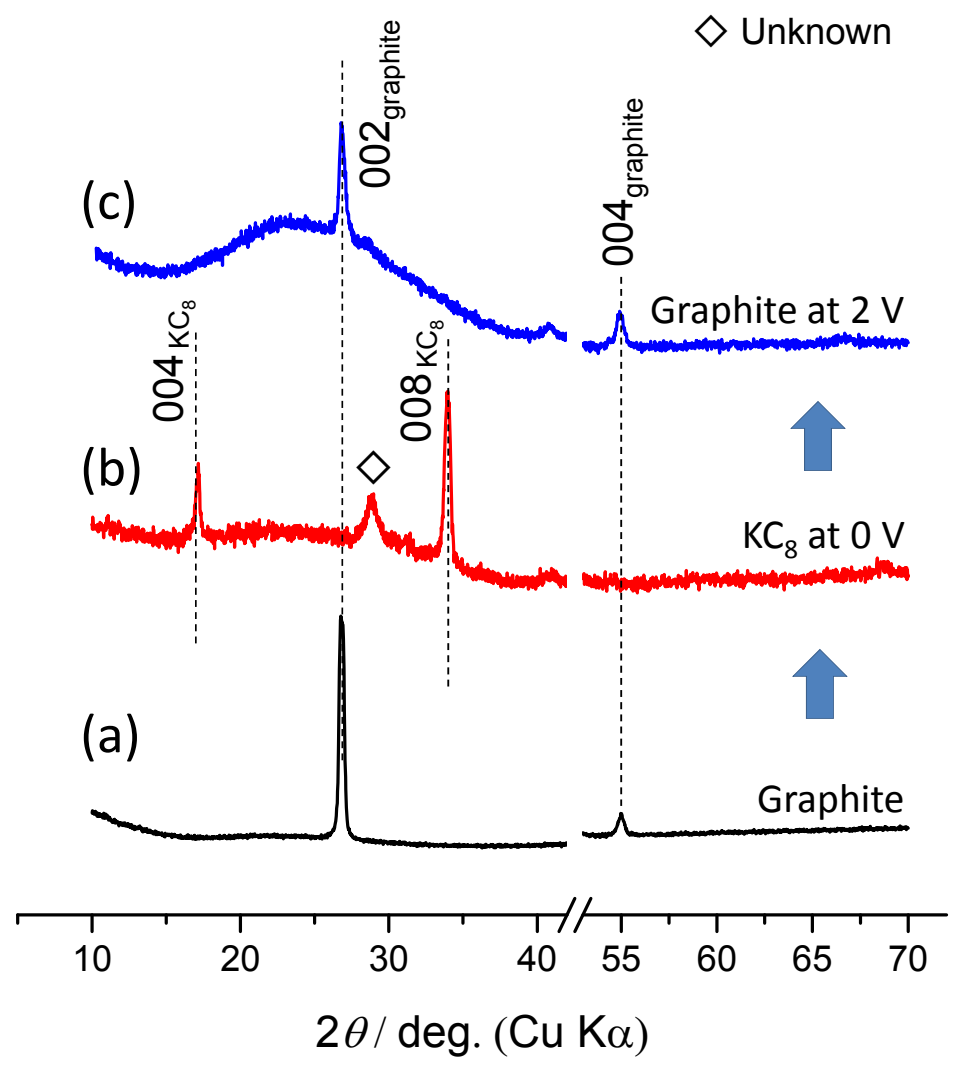

Figure 2. Ex-situ XRD patterns of graphite-PANa electrode: (a) as prepared, (b) after first reduction at $0.0 \mathrm{~V}$, and (c) after oxidation $2.0 \mathrm{~V}$ in $\mathrm{K}$ cells. 
(a)
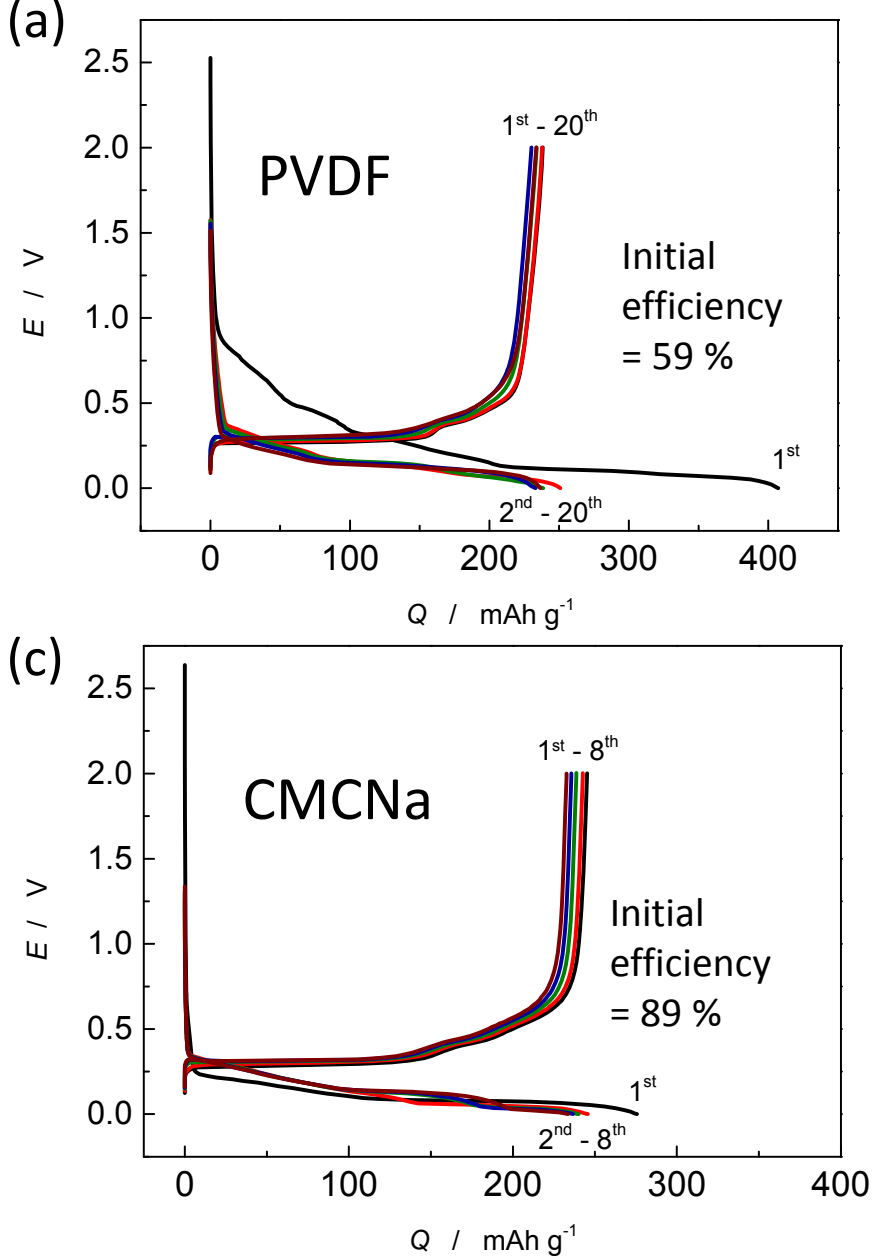

(b)
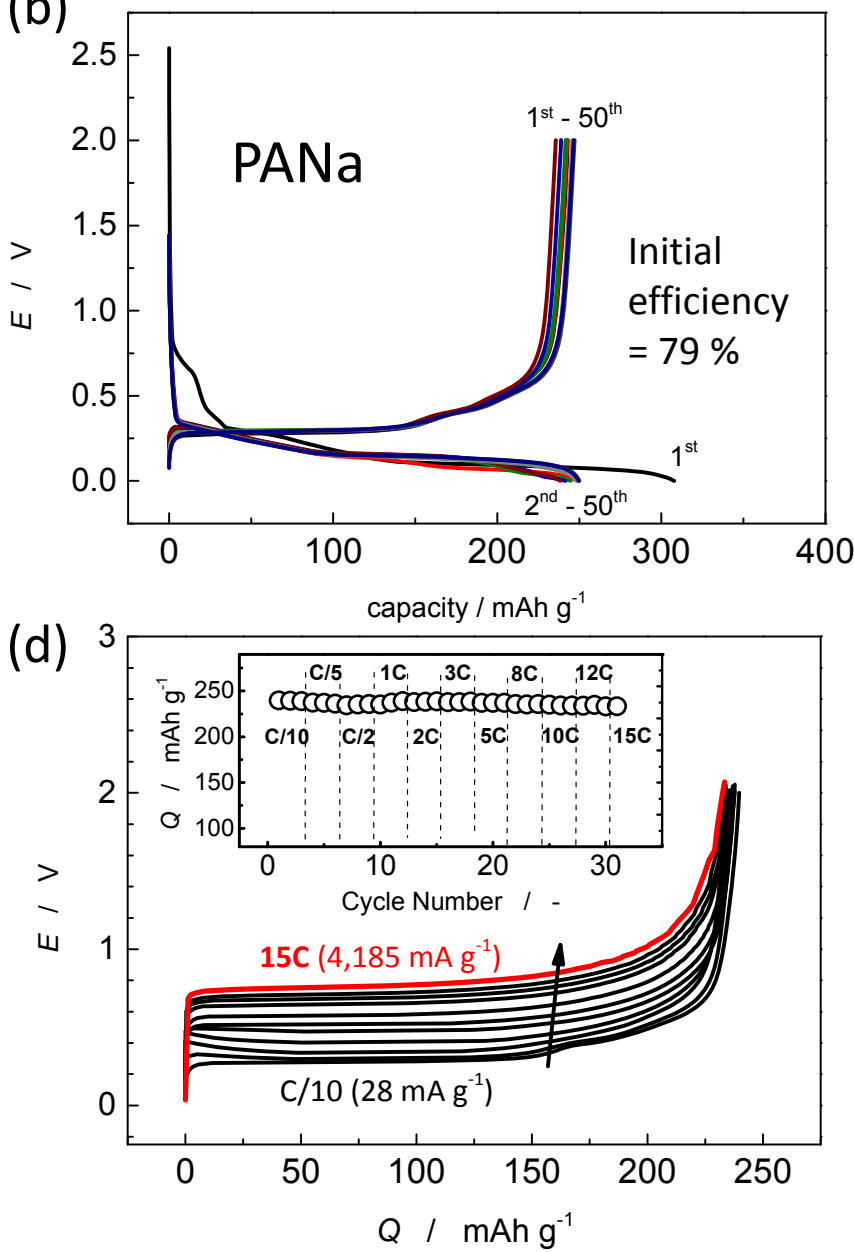

Figure 3. Charge-discharge curves of graphite electrode formed on Al foil with (a) PVDF, (b) PANa, and (c) CMC binders in $1 \mathrm{~mol} \mathrm{dm}^{-3} \mathrm{KFSI}$ EC:DEC of $\mathrm{K}$ cells, and (d) oxidation-rate capability for the PANa electrode. 
Table 1. Comparison of alkali metals' characters as an ionic carrier of nonaqueous rechargeable batteries.

\begin{tabular}{|c|c|c|c|}
\hline$A=$ & Lithium & Sodium & Potassium \\
\hline Abundance & + & +++++ & +++++ \\
\hline Relative atomic mass / - & 6.9 & 23 & 39 \\
\hline Shannon's ionic radii of $A^{+} / \AA$ & 0.76 & 1.0 & 1.4 \\
\hline Melting point / ${ }^{\circ} \mathrm{C}$ & 179 & 98 & 64 \\
\hline $\mathrm{E}^{\mathrm{O}}\left(\mathrm{A}_{\text {aq. }}^{+} / \mathrm{A}\right) / \mathrm{V}$ vs. SHE* & -3.040 & -2.714 & -2.936 \\
\hline$E^{O}\left(A^{+}{ }_{p C} / A\right) / V$ vs. SHE* & -2.79 & -2.56 & -2.88 \\
\hline $\mathrm{E}^{\mathrm{O}}\left(\mathrm{A}^{+}\right.$aq. $\left./ \mathrm{A}\right) / \mathrm{V}$ vs. $\mathrm{Li}^{+}{ }_{\text {aq. }} / \mathrm{Li}^{*}$ & 0 & 0.326 & 0.104 \\
\hline $\mathrm{E}^{\mathrm{O}}\left(\mathrm{A}^{+}{ }_{\mathrm{PC}} / \mathrm{A}\right) / \mathrm{V}$ vs. $\mathrm{Li}_{\mathrm{PC}}^{+} / \mathrm{Li}^{*}$ & 0 & 0.23 & -0.09 \\
\hline
\end{tabular}

* The standard electrode potentials at $279.15 \mathrm{~K}$ are calculated from standard molar Gibbs energy of hydrated and PC-solvated $\mathrm{A}^{+}$ions. Ref.) Marcus, Y., Pure Appl. Chem., 1985, 57, 1129. 